\title{
Expectant Management of Severe Preeclampsia Remote From Term In A Rural Setting of Niger Delta, Nigeria: Is It Time to Define a Protocol?
}

Mbachu Ikechukwu Innocent ${ }^{1^{\star}}$, Eleje George ${ }^{1}$ and Osuagwu Ihechimere Kelechi ${ }^{2}$

${ }^{1}$ Nnamdi Azikiwe University Teaching Hospital, Nnewi, Ananmbra State, Nigeria

${ }^{2}$ Madonna University Teaching Hospital, Elele, Rivers State, Nigeria

"Corresponding author: Mbachu Ikechukwu Innocent, Department of Obstetrics and Gynaecology, Nnamdi Azikiwe University Teaching Hospital, Nnewi , Ananmbra State, Nigeria, Tel: +2348035031726; E-mail: imbachu@yahoo.com

Received date: June 22, 2015, Accepted date: July 27, 2015, Published date: August 3, 2015

Copyright: $\bigcirc 2015$ Innocent MI, et al. This is an open-access article distributed under the terms of the Creative Commons Attribution License, which permits unrestricted use, distribution, and reproduction in any medium, provided the original author and source are credited.

\begin{abstract}
Background: Severe preeclampsia is one of the leading causes of maternal and perinatal mortality worldwide. Management of cases remote from term poses a great challenge to the caregiver and the patient. This is more pronounced in developing countries with limited resources and high premium on children. This article highlighted the challenges in the management and we presented a successfully expectant management of a case in a rural setting.
\end{abstract}

Case presentation: We presented Mrs JV, a 33 year old booked G7P1 with no living child who presented at the gestational age of 24 weeks plus 3 days with severe hypertension and proteinuria. Expectant management was instituted and pregnancy was ended via an emergency caesarean section at 29 weeks of gestation with delivery of extreme low birth baby. Both mother and baby are in good health.

Conclusion: Management of severe preeclampsia remote from term should be individualized and can be feasible in a rural setting in developing countries. Availability of tertiary health institutions in rural settings will help in the management of these patients.

Keywords: Expectant management; Severe preeclampsia; Remote from term; Rural setting

\section{Introduction}

Severe pre-eclampsia occurring remote from term (mid trimester) is a decision making dilemma for the obstetrician. Although some obstetricians may choose to manage these patients conservatively, hoping to achieve fetal lung mature before delivery, the general recommendation is that women with severe pre-eclampsia should be delivered after stabilization to avert maternal complications [1,2]. Since the disease is progressive and there is no medical treatment, delivery is always in the best interest of the mother [2]. However, while some institutions consider delivery to be definitive therapy for all cases, regardless of the gestational age, others recommend prolonging pregnancy in most cases of severely premature pre-eclamptic gestations until one of the following occurs: development of fetal lung maturity, development of fetal or maternal distress, or achievement of gestational age of 34 to 36 weeks of gestation $[1,3,4]$.

It is a common observation that some considerable women are unwilling to give consent for termination of pregnancy after stabilization. The major questions remain what should we do when the mother and her partner refused consent for termination of pregnancy in severe pre-eclampsia remote from term. Results have sometimes given unexpected good materno-fetal outcomes $[1,3]$. On the basis of this experience, we aimed to report this case (among several similar reports) to highlight existing materno-fetal survival following conservative management of severe pre-eclampsia remote from term in a rural community in a developing countries.

\section{Case Presentation}

Mrs. J V was a 33 yr old booked G7P1+5 with no living child. The gestational age at presentation was 24 weeks and 3 days in the antenatal clinic of Madonna University Teaching Hospital on $15^{\text {th }}$ August 2014 due to increased blood pressure. There was no associated history of headache, dizziness, epigastric pain, nausea and vomiting but there was oedema on both lower limbs. The blood pressure was normal until the day before presentation. Her only confinement in 2011 was complicated by Preeclampsia and abruption placenta. It was ended through emergency caesarean section at 35 weeks of gestation. The neonate died 30 minutes after delivery.

She had 2 episodes of termination of pregnancy and subsequently had three episodes of recurrent miscarriages. There was no history of change of partner.

On examination she was afebrile, not pale, anicteric, not dehydrated, but had bilateral pitting oedema up to the knees. Her blood pressure was 180/110 $\mathrm{mmHg}$, heart sounds 1 and 2 were heard and there was no added sound. The respiratory rate was 16 cycle per minute and the chest was clinically clear.

Abdomen was enlarged, moves with respiration and there was presence of a midline sub-umbilical scar. The symphysio-fundal height was $23 \mathrm{~cm}$ and the fetal heart rate was 150 beats per minutes.

An assessment of severe pre-eclampsia remote from term was made and she was then counseled and admitted into the prenatal ward for stabilization, investigations and delivery. 
On admission the blood pressure was190/110 mmHg. She was given $5 \mathrm{mg}$ hydralazine intravenously slowly over 10-15 mins and placed on antihypetensives, daily low dose aspirin $(75 \mathrm{mg})$ and haematinics.

The vital signs were monitored. The following investigations were done: serum electrolyte, urea and creatinine, full blood count, clotting profile, liver function test and Abdominopelvic ultrasound. Daily urine output was charted and it remained normal.

Her blood pressure remained uncontrolled after 48 hours on admission. A course of dexamethazone was given. Magnessium sulphate was also given according to Pritchard's regimen.

On day five after admission, she was counseled for termination of pregnancy but she and her husband refused termination of pregnancy and stated that they wanted to continue carrying the pregnancy till about age of fetal viability ( 28 weeks). The decision to continue conservative management was made. She did daily ward urinalysis, weekly full blood count, liver function test, and serum electrolyte urea and creatinine and abdominopelvic ultrasound.

The investigation results in the first week and second week on admission were essentially normal. Daily ward urinalysis showed persistent $2+$ of proteinuria.

In third week of admission, platelet count was 96 (100-300check unit) and haemoglobin $(\mathrm{Hb})$ was $8 \mathrm{gm} / \mathrm{dl}$ but clotting profile was normal. She was again counseled on termination of pregnancy, which she refused. She was transfused with 2 units of fresh whole blood.

In the fourth week of admission, liver function test, serum electrolyte, urea and creatinine and full blood count were normal ( $\mathrm{Hb}$ was $10 \mathrm{~g} / \mathrm{dl}$ ) and ultrasound showed oligohydramnios. She was observed closely for signs of imminent eclampsia. Other investigations done were all normal. However, the blood pressure still remained uncontrolled and proteinuria remained $2+$, sublingual nifedipine 20 mg was added in order to achieve a better blood pressure control and reduce the use of IV Hydralazine. After 3 days of sublingual nifedine the blood pressure reduced to $160 / 100 \mathrm{mmhg}$ and sublingual nifedipine was withdrawn while she continued the other drugs as prescribed earlier.

In the fifth week, patient was noted to have ascites from ultrasound done showed oligohydramnious and patient was noted to have ascites. PCV done was $27 \%$ and platelet count had dropped to 84 cells per cubic millimeter. Urinalysis was now showing $3+$ of proteinuria. A repeat course of dexamethasone was also given over 24 hours.

The emergency $\mathrm{c} / \mathrm{s}$ was done at GA of 29 weeks +5days. Intraoperative findings included previous midline subumblical scar, moderate adhesions, massive maternal ascites of about $1.5 \mathrm{~L}$, poorly formed lower uterine segment, a live female neonate with birth weight of $0.8 \mathrm{~kg}$ and Apgar score of 5 in one min and 7 in five minutes $\left(5^{1} 7^{5}\right)$, and estimated blood loss of $400 \mathrm{mls}$. Baby was admitted into the special care baby unit.

Following delivery her blood pressure reduced and stabilized on day 3 post op and tablet Aldomet was reduced to $250 \mathrm{mg}$ thrice daily. She also received prophylactic antibiotics and hematinics. Post- operative period was not remarkable. Ultrasound done showed marked ascites but no organomegaly. The plan was to continue anti-hypertensives and monitor the patient with daily weighing, daily measurement of abdominal girth and daily urinalysis. This showed a progressive reduction in both weight and abdominal girth and the blood pressure was normal and urinalysis done showed no proteinuria. She was discharged on 11DPO.

\section{Baby}

She was admitted into Special Care Baby Unit following delivery via emergency Caesarean section. A diagnosis of preterm extreme low birth weight at risk of sepsis was made and she was managed inside an incubator; intravenous (I.V) antibiotics, I.V fluids and Nystatin suspension were administered for one week. She was also commenced on expressed breast milk via nasogastric tube. She maintained good temperature control and was normoglycaemic throughout admission. Patient had hypocalcaemia which was corrected using intravenous calcium gluconate. She was commenced on iron syrup on at 5 weeks of life and on the 43rd day of admission she developed anaemia (packed cell volume of 15\%) and was subsequently transfused with $20 \mathrm{mls}$ of fresh whole blood. She also had a repeat transfusion at day 57 of life on account of packed cell volume of $20 \%$. She started suckling at the breast when she attained the weight of $1.79 \mathrm{~kg}$ on day 70 of life and was subsequently discharged home on 76th day of admission with a weight of $1.9 \mathrm{~kg}$ on iron syrup. She was immunized before discharge and scheduled for follow-up appointment in 2 weeks.

\section{Discussion}

Preeclampsia is one of the leading causes of maternal and perinatal mortality worldwide $[5,6]$. The incidence is higher in developing countries with worse case fatality. This is because of many challenges facing the health sector. These challenges are more pronounced in the rural areas of developing countries where lack of personnel, dearth of healthcare infrastructures, poverty, ignorance and illiteracy are rampant. Elele, is a rural area located in the Rivers state in the Niger delta of Nigeria. The literacy rate is low and most of the women are traders and farmers.

Recent evidence has shown that proteinuria alone has a poor predictive value of maternal and fetal outcome in women with preeclampsia [7,8]. This observation combined with the use of $\mathrm{MgSO}_{4}$ as seizure prophylaxis has led to conservative management of selected cases of preeclampsia. One intriguing question is: could we commence expectant management after intial administration of magnesium sulphate for seizure prophylaxis, as was seen in the index case report?

We carried expectant management for so many reasons. Our patient was highly motivated which may be connected with her bad obstetrics history, she has no living child and was living in an environment with very high premium on children. Our centre is tertiary health institution though it is located in a rural setting.

Expectant management should be considered in a setting where the disease is not progressive as evidenced by absence of clinical or laboratory feature of severe disease. It also has a role to play in a setting where the woman is strongly motivated despite advice to the contrary. In developing countries with high premium on children, women are usually strongly motivated to achieve childbirth after initial stabilization, which was true in this case. Low dose aspirin and repeat dexamethasone were use in the management. Their contribution to the successful management of this case will need further evaluation.

As was done for our patient, hospitalization is an essential part of this management because it is necessary to evaluate the full extent of the effects of the disease process on the mother and the fetus. Only in this way can the patient experience minimal physiologic stress while 
Citation: Innocent MI, George E, Kelechi OI (2015) Expectant Management of Severe Preeclampsia Remote From Term In A Rural Setting of Niger Delta, Nigeria: Is It Time to Define a Protocol?. J Hypertens 4: 203. doi:10.4172/2167-1095.1000203

Page 3 of 3

undergoing the laboratory procedures needed to assess maternal conditions, especially renal and hepatic functions.

Careful patient selection is very important for a good outcome. Detailed history, examination and investigations will rule out features of progressive disease. Our patient was monitored clinically and by the use of laboratory investigations. Antepartum surveillance should also be instituted to monitor the fetus. As in our case, we found that it was possible to prolong pregnancy by an average of five weeks. Liver function test, renal function test of the woman were within normal limits. Only proteinuria, platelet count and haemoglobin concentration were consistent and significantly abnormal. However, Schiff and colleagues [9] concluded that the level of proteinuria and the rate of increase in proteinuria during conservative management are not important predictors of maternal and perianal outcome.

Optimal time of delivery is determined by the state of the mother, fetus and the salvage rate in the environment. The decision to deliver was occasioned by features of worsening disease. Therefore, we aimed to designate the time of delivery in such a fashion that both mother and fetus were best able to tolerate delivery while providing the fetus with minimum chance of extra uterine survival.

We conclude that in selected cases, with close monitoring and supervision, conservative management can be attempted in cases of severe pre-eclampsia remote from term. This is especially in developing countries where neonatal intensive care is either nonexistence or beyond the reach of many patients. However, where the facilities and personnel are available to improve the neonatal outcome without compromising the maternal health, the management of pre-eclampsia in developing countries should adopt the WHO and other recent guidelines. The successful management of this patient highlights the need to expand the maternity services in rural settings.
This will put smiles on families and reduce the maternal mortality occasioned by high patronage of quacks.

\section{References:}

1. Sibai BM, Barton JR (2007) Expectant management of severe preeclampsia remote from term: patient selection, treatment, and delivery indications. Am J Obstet Gynecol 196: 514.e1-e9

2. Sezik M, Ozkaya O, Sezik HT, Yapar EG (2007) Expectant management of severe preeclampsia presenting before 25 weeks of gestation. Med Sci Monit 13: CR523-527.

3. Abdel-Hady el-S, Fawzy M, El-Negeri M, Nezar M, Ragab A, et al. (2010) Is expectant management of early-onset severe preeclampsia worthwhile in low-resource settings? Arch Gynecol Obstet 282: 23-27.

4. Bombrys AE, Barton JR, Habli M, Sibai BM (2009) Expectant management of severe preeclampsia at $27(0 / 7)$ to $33(6 / 7)$ weeks' gestation: maternal and perinatal outcomes according to gestational age by weeks at onset of expectant management. Am J Perinatol 6: 441-446.

5. Hutcheon JA, Lisonkova S, Joseph KS (2011) Epidemiology of Preeclampsia and other hypertensive disorders of pregnancy. Best Pract Res Clin Obstet Gynaecol 25: 391-403.

6. Khan KS, Wojdyla D, Say L, Gulmezoglu AM, Van Look PF (2006) WHO analysis of causes of maternal death: a systemic review. Lancet 367: 1066-1074.

7. Von Dadelsin P, Payne B, Li J, Ansermina JM, Broughte Pipkin F, et al. (2011) Prediction of adverse maternal outcomes in preeclampsia. Development and validation of the fullPIERS model, PIERS study group. Lancet 377: 219-227.

8. World Health Organization recommendation on Prevention and Treatment of Eclampsia and Preeclampsia 2011.

9. Schiff E, Peleg E, Goldenberg M, Rosenthal T, Ruppin E, et al. (1989) The use of aspirin to prevent pregnancy-induced hypertension and lower the ratio of thromboxane A2 to prostacyclin in relatively high risk pregnancies. N Engl J Med 321:351-356. 